\title{
Experimentation in Institutions: Ethics, Creativity, and Existential Competence
}

\author{
Aislinn O'Donnell ${ }^{1}$
}

Published online: 15 February 2017

(C) Springer Science+Business Media Dordrecht 2017

\begin{abstract}
The existential, experiential, ethical, pathic and pre-pathic dimensions of education are essential for the creative composition of subjectivities in institutional spaces, yet educational research and policy tend increasingly to privilege technical discourses and prescriptive approaches both when evaluating 'what is effective in education' and when determining educational policy. This essay explores those aspects of the educational experience and educational institutions that are often felt and sensed pre-cognitively by students, parents and teachers, but are seldom given further elaboration or articulation in educational research. We will reflect on what is meant by the experience of education and experience in education, including the struggles to make sense of or understand something, the surprises that strike pre-reflectively, and the ways in which such moments are noticed, pursued, and explored rather than reflexively 'evaluated'. We then explore the idea of experimentation in institutions, in particular in relation to the range of concepts that Jean Oury introduces in order to move our attention and awareness to questions of experience, existence, atmosphere, and the pathic - the way in which we undergo, sense and participate in the world prior to cognition and the desire for mastery and control of our encounters. Finally, we address the question of the ethics of institutions.
\end{abstract}

Keywords Creativity - Experimentation - Educational experience $\cdot$ Institution · Existential competence $\cdot$ Singularity $\cdot$ Ethics $\cdot$ Jean Oury $\cdot$ Pathic $\cdot$ Guattari $\cdot$ Deleuze

\section{Introduction}

Teachers' capacity for sensitive attunement to the existential, experiential, ethical, pathic and pre-pathic dimensions of education is essential for the creative composition of subjectivities in institutional spaces, yet educational research and policy tend increasingly to

Aislinn O’Donnell

aislinn.odonnell@nuim.ie

1 Education Department, Maynooth University, Maynooth, Co. Kildare, Ireland 
privilege technical discourses and prescriptive approaches when evaluating "what is effective in education' (O'Donnell 2013). This essay reflects on aspects of the educational experience and educational institutions that are often felt and sensed by students, parents and teachers, but are seldom privileged as a topic for educational research or thematised in teacher education. Given their apparent abstraction, concepts like those in the above list might seem divorced from the tumult of everyday pedagogical practice and the pragmatics of education. Nonetheless, they tend to be intuitively familiar to people who spend time in educational institutions, be they teachers, students, parents or other staff. Different schools and classrooms can feel different and those differences make a difference to the educational experience (the classroom that makes you freeze with tension when you walk through the door; the palpable sense of kindness and welcome in some staffrooms..). Rather than imagining that learning happens all the time regardless of context in an upward curve of progress and consolidation, like a reliable conveyor belt, attention is here paid to the lived experience in and of education, in particular those moments at which something takes hold, something moves, the world opens, and desire, interest and energy feel almost tangible (Maldiney 1991). Coming to notice such moments in one's students involves learning to attune oneself to the atmospheres and milieus of educational settings and identifying the pre-conditions for these shifts and transformations involve engaging in an honest analysis of institutional spaces. Reflecting on the educational experience allows us then to think of pedagogical or learning experiences as well as other encounters and experiences in institutional and community settings. The concept of educational experience is here mobilised in a way that is deliberately ambiguous in order to allow us to imagine both those experiences that could be called educational as well as the experiences that take place in educational institutions.

Moments of encounter, questioning, wonder, and surprise in education-what Olsson (2009) calls 'magical moments' - can easily dissipate if not noticed and attended to, but so too can the conditions for their emergence be cultivated in institutions if given due care. Attention to the atmosphere of institutions involves working with others to both analyse and care for institutions in order that, at a minimum, harm is not done to those participating in them. Existential competence, creativity, ethical sensitivity and judgement can be developed by teachers, so that those moments when 'something happens' for a student can be noticed and then supported. There is a difference between this kind of approach that foregrounds the idea of existential competence and those discourses interested in innovation and creativity more generally. In the former case, the specificity, indeed singularity, of institutions themselves is foregrounded, and they are understood to be experimental sites that seek to attend to the educational experience itself; creative pedagogy is not just a matter of new content, theories of learning, or pedagogical strategies. Those experiences that we could call educational look beyond the self, as students (and their teachers) encounter the world through fresh eyes, refining their sensibility and perception, such that the world is renewed and experienced anew (Biesta 2011). The purpose of this essay is to explain why this matters in education and show to the importance of paying attention to the atmospheres of institutions, and the ways in which different atmospheres undermine or support learning and thinking. Refining one's sensitivity to the quality of lived experiences in institutional settings helps one to support students whilst also enabling one to judge the potential for experimentation with institutional conditions such that they can support the educational encounter.

Jean Oury $(2005 ; 2007 b)$ argues that existential competence involves developing the ability to: (1) respond to the other as 'other'; (2) support the other's abilities to take on responsibility; and (3) co-create spaces that invite the composition of new subjectivities. 
This involves both practice and experience and a subtle sensitivity to shifts in atmosphere and dynamics. Thinker-practitioners like Jean Oury, his brother Fernand, and their friend and colleague François Tosquelles created living institutions that evolved from their attention to practice but that were formed by ideas, just as emergent concepts allowed for different ways of understanding, being and sensing. Their ideas and commitments inflected and influenced the ideas of thinkers like Gilles Deleuze, Félix Guattari, and Frantz Fanon. In 'living institutions', that importance and attention is given to experience is evidenced by the active encouragement of "grasping experimentation" and the explicit commitment to the cultivation of ethical sensibilities that can work with subtle and invisible dimensions of institutions and human subjectivity, that is, with the transversal relations that can either close down or open up a human life. Certain classrooms and institutions create atmospheres that can give rise to the possibility of an ethic of the 'with' and the possibility for existential encounters. Others make this virtually impossible. Part of this process involves creating the conditions for the unpredictable and the surprising to arise. When the opposite occurs, institutions become necrophiliac, preferring what is dead, stable, and predictable over what is alive, animated, and lively. In order to find images and metaphors to help us to talk about different experiences of and in education, we begin with Ada Jaarsma's concept of the 'pedagogical tomato'.

In our accompaniment of this image/concept of the 'pedagogical tomato', we reflect further on what is meant by the experience of education, including the struggles to make sense of or understand something, the surprises that strike pre-reflectively, and the ways in which such moments are noticed, pursued, and explored rather than reflexively 'evaluated'. We then explore the idea of experimentation in institutions, in particular in relation to the range of concepts that Oury introduces, in order to move our attention and awareness to questions of experience, existence, atmosphere, and the pathic - the manner in which we undergo, sense and participate in the world prior to cognition. Finally, we address the question of the ethics of institutions.

\section{Pedagogical Tomatoes}

It's a Wellington thing —it's a student thing,' said Victoria rapidly, coming up on her elbows. 'It's our shorthand for when we say, like, Professor Simeon's class is "The tomato's nature versus the tomato's nurture", and Jane Colman's class is "To properly understand the tomato you must first uncover the tomato's suppressed Herstory" — she's such a silly bitch that woman — and Professor Gilman's class is "The tomato is structured like an aubergine", and Professor Kellas's class is basically "There is no way of proving the existence of the tomato without making reference to the tomato itself", and Erskine Jegede's class is "The post-colonial tomato as eaten by Naipaul". And so on. So you say, "What class have you got coming up?" and the person says "Tomatoes 1670-1900." Or whatever.

Zadie Smith (2002) On Beauty. p. 312.

In her mischievous essay on universal design and animal politics, Ada Jaarsma draws upon Smith's image of the tomato in order to develop and extend her own concept of the "pedagogical tomato". To explain what she means by this, she describes the experience of an analytic philosophy seminar on ethics that "presented ethical thinking as ideally neutral, objective, largely contextless, dependent on the type of rational reflection that can only 
take place by distancing oneself from the messy contingencies of bodily and historical life" (Ada Jaarsma 2016 p. 205). Her friend described that same class as "a tomato in outer space". Jaarsma reflects on this, noting that it was impossible to even "inquire into the 'manure' of the course content" (ibid. p. 206)—those assumptions and exclusions that make possible the claims to objective rationality in the course. Her friend thinks about her own pedagogical tomato as a teacher-to smell the tomato's manure, asking her students to fall in love with literature and philosophy, whilst acknowledging their complicity and implication in the "colonial, racialising contexts, or manure, of the curriculum" (ibid. p. 206). Another kind of tomato could be hylomorphic Bologna models of pedagogy that lay out templates to be applied to a raw subject matter, occupying an Archimedean point, a view from nowhere, a 'god trick', insisting on neutrality, asymmetrical agency and causative powers. (One can imagine how a Bologna tomato might taste.) Some tomato scripts see teaching as causal, objective and predictable rather than occasioned, complex and non-linear (ibid. p. 207). By mobilising the somewhat surreal and open image of the tomato it becomes easier to elaborate singular descriptions that are able to communicate the specific feel and qualitative experience of diverse classes as well as the sensibility of different teaching styles, such that one can resist the temptation to generate generic tomatoes or perfect tomatoes that might be readily transferable from one teacher to another.

Disillusionment has a tendency to set in amongst novice student teachers and some teachers when they discover that theories of how to teach don't dispel the messiness of classroom practice-unfortunately, as they come to learn, generic methodological tomatoes don't have causative and magical powers. For example, the behavioural management tomato falters when deliberately choreographed movements and gestures in the classroom fail to elicit the obedient and docile responses of children that studentteachers are taught to expect. This is not to suggest that theories, methodologies, and ideas are unimportant, but rather that they risking taking on the aura of mythical tomatoes when imagined to hold the solution to every pedagogical situation and problem. Indeed, the 'what works' and 'systematic review' discourses that lay claim to the ability to grow the perfect tomato-rather like the tomato in outer space-help little with navigating and understanding the variegated tomatoes of classroom life. In this regard, Jaarsma writes, "Whether we think of standardised testing and other pre-set templates or the outcomes-based orientation of accreditation, there is a prevailing ethos that demands that all varieties of tomatoes yield the same crop" (ibid p. 208). Metaphors and images here like the soil, culture, weather, temperature, climate and atmosphere of different classrooms on different days and at different times communicate the vicissitudes and affective tenors of life in education. Indeed, gardening and climatic metaphors, so much a part of the educational imaginary, might be put to a more diagnostic and critical use than that rather more familiar aspirational one that populates student-teacher discourse (the gardener-saviour).

The mobilisation of this under-determined image/concept of the 'tomato' helps us to think about images that both shape and convey educational imaginaries, as well as the epistemological presuppositions that privilege generic or universal responses to the questions and problems of education. It invites us to think about the singular taste and look of different individual tomatoes, that is, the different qualities and feel of our classrooms, teachers, subjects, and schools. This is not so much a question of privileging only one kind of tomato, but of noting which tomatoes are dried out, dessicated, mechanical, shrivelled, succulent, complex, tasty or strange-looking. In this way we are better positioned to locate tomatoes that are not nourishing, and foster the diverse tomatoes in education that allow for 
something to happen for the students, teachers and other stakeholders. This involves cultivating organisational cultures. Rather like the 'manure' of which Jaarsma speaks, certain 'cultures' encourage something akin to bacterial and vital aliveness that germinates and is generated in different ways in different contexts, even if it requires constant attention to keep it fed and growing. Perhaps because of the current pressures on educators to ensure predictable outputs, educational practice and research can sometimes feel like drone tomatoes, finely honed algorithms to ensure perfection, replicability, and equivalence of output. This kind of tomato is at best quite good at perfecting a delimited task but not very good at responding creatively or with insight to the rhythms of classroom life and the multitude of subjectivities that occupy such spaces, unless it imposes its own modus operandi. Hannah Arendt observes in this regard, "the trouble with modern theories of behaviourism is not that they are wrong, but that they could actually become true" (1958 p. 322). This risk appears more and more acute as classrooms are increasingly shaped by new managerialism, systemic review, measurable methods of validation, performativity, and systems that only count certain things, most of which have little to do with, or interest in, those experiences that we might call 'educational'. Emphasising only measurable, tangible and predictable outputs distorts the nature and experience of educational spaces and occludes the different potentials offered by and through the different genealogies, materialities, arrangements and encounters of different spaces. It also undermines professional autonomy, judgement and creativity, and the possibility of situated knowledges that work with singular cases. None of this is new, of course. But even if it is not new, it seems it is not heard.

Even if those experimental models such as randomised controlled trials that operate with uni-linear causation and clearly distinguishable inputs and outputs were capable of effectively identifying key variables in agricultural or clinical trials, they can't hope to grasp the variegated nature and experiences of education (Biesta 2007). Yet, the myth that such models have located or will locate the solution to the questions of how to teach and how to learn gives some people comfort, certainty and authority. However, it is difficult to imagine how one might be able to distil, purify and control the complex environments of schools and classrooms in order to isolate only those phenomena that are deemed to support teaching and/or learning in any situation, regardless of context. And even if one could, what would be the implications of so doing for the lived experience of students and teachers? To imagine inventing a 'magic' formula with causal powers that can ensure all children will learn 'effectively' perpetuates a delusion that ignores the complexity of the human psyche and subjectivity. The behavioural imaginary that dominates much educational research views the operations 'inside the black box' as irrelevant, what is seen to matter is only what is seen and shown: what is visible, what is transparent. In its resistance to speculative experimentation, inquiry and exploration, this privileges a model of epistemology that looks through a lens, maintaining its distance, and showing and documenting what is there, that is what it has produced, comparing it with its own idea of what should be there, but not what is possible. Making it explicit, so to speak, ought not to just be concerned with those elements of experience that can be seen, produced, made objective or formalised whilst ignoring others that are sensed and felt, especially since those invisible, experimental, experiential, intangible, atmospheric experiences of education tend to be described as of transformative significance in stories of students and teachers. What then gets in the way of educational experiences? What stops institutions from being living institutions? 


\title{
The Logic of the Camp
}

In one of my philosophy classes in prison, one of the men quipped that 'they'd prefer it if we were all corpses here, no mind, no resistance, easy to cart about'. He wrote a humorous and poignant poem about institutional life after our conversation. It is called 'Life in a Freezer'.

\author{
I'm like a carcass \\ No head, no legs \\ I can't run away and \\ I can't think for myself. \\ They think for me \\ They slide me from freezer to freezer \\ I am now in the long-term freezer \\ Hoping to go to the short-term freezer \\ They might thaw me out \\ So I can think for myself \\ And make a choice
}

The poem communicates the sense that life is suspended in the prison; one is treated as one of the living dead. When Oury (2007b) says that ethics is not simply about being responsible for the other, but also being responsible for the responsibility of the others, he is also thinking about how to respond to the deadening effects that segregated institutions have on the subjectivities housed within them. There is an atmosphere or quotidian climate of weary sameness, from the lock up and lock down times to always knowing what dinner is on which day. This is the 'logic of the camp'.

Oury (1998) despairs of the 'logic of the camp'. This image is not used as a provocation or polemic, but rather it is invoked in order to communicate a real concern at the way in which hyper-segregation, non-proximal relations, isolation, and bureaucratic procedure trump too readily the experiential realities of the living and singular human beings housed within institutional spaces. Forms of social alienation perpetuated outside institutions are also entrenched within the space itself, separating people on the basis of perceived competence or sharply delineating roles and functions (Oury 2007b). In this regard, Tosquelles (2003) notes the way in which the person who is poor is not only made aware of his or her poverty but also experiences a sense of shame, guilt and self-blame at his or her lived situation. This social alienation is carried into institutional settings, for example, defining the relations between teachers and parents in certain schools. In the distribution of tasks within institutional settings, hierarchies, roles and privilege amongst workers is consolidated and patients or students are positioned in specific asymmetrical relationships with power-holders. He calls this the 'school as barracks'.

Dynamics and structures in institutions are never easy to shift or transform, in particular when parties involved say 'ça va de soi' or that's obvious, evident, common sense, how things must be. Deleuze labels this the dogmatic or orthodox image of thought, that is, an image of thinking that functions on the basis of recognition, identity and sameness, classifying all that exists into pre-existent categories. The dogmatic image of thought's power comes from the claim to common-sense of "Everyone knows" (1994, p. 130). Deleuze argues that this orthodox or dogmatic image of thought "everyone knows" or "it's obvious" serves to moralise and sanction and views it as complicit with power, operating as an internal barrier to change in institutions: both Tosquelles and Oury identify the 
mentality of the technocrat and bureaucrat as of most danger to people in institutions. Cognitive and epistemological norms perpetuated through the technocratic imaginary promote a false sense of certitude and effectiveness, and institute affective norms of fear, deference to authority, and refusal of criticism. In this respect, Oury (2007b), following Tosquelles, makes a distinction between the Etablissement, which is related to the State, and the Institution, a living and collective affair and common endeavour. In the case of the Établissement, its logic is mechanical, insensitive and bureaucratic and presupposes that abstractions can have meaning independent of context, and that key variables and causal factors can be isolated and distilled from complex institutional environments. Tasks and functions set out by the bureaucrat include meeting targets, prescribing a-contextual, preset outcomes and insisting on accountability procedures that utilise measurable indicators of impact. This logic is reminiscent of what could be termed 'drone imaginaries' that privilege autonomy over relationships and connections, behaviour over experience, and perfection over fallibility.

Ratnapalan and Reggio (2012) note that the preference for the gnostic, that which is explicit, objective and general, occludes the pathic mode of sensing, described by Erwin Straus, and mapped somewhat above in our descriptions of the 'feel' and 'atmosphere' of different institutions. Straus found the implicit 'Cartesian-ism' of behaviourists frustrating because they amputated the possibility for deeper understanding of the human being, eliminating questions of the phenomenal world and existence, and disregarding sensory and sensible experience, including the pathic dimensions of existence (Ratnapalan and Reggio 2012). Straus understood the pathic to be both dynamic and ineffable, the preconceptual communication we have with appearances by virtue of simply existing.

Jean Oury argues that we need to care for institutions, and we suggest that creating the conditions for educational experiences involves acknowledging the role of the pathic. In the case of schools, rather than thinking about curriculum, methodologies, family/ school/community partnerships, or even teacher identity, what is first required, is what Tosquelles called 'institutional analysis' to identify how the institution works, what seems to matter for people in it, what is noticed or seen as valuable, and what is ignored. Indeed, Oury argues that one needs to 'sweep' the institution, performing an asepsis, clearing it of prejudgements and preformed ideas, 'working the invisible', just as one would 'sterilise' before surgery in order to resist the stultifying logic of the 'ça va de soi' (2007a, 2007b). This does not mean that a 'neutral' position ought to be adopted but rather that an effort needs to be made to identify, and rid the space of, those clichés and presuppositions that are preventing effective encounters and relationships. Such a critical evaluation of the institution itself makes it less easy to blame outside parties or circumstances for the lived experiences and activities of, for example, the children within an institution like a school. It asks questions like: In what ways is this institution silencing the voice of children? What kinds of prejudices and prejudgements are ordering the structuration of relationships with different children? What image do I have of myself as a teacher/cleaner/janitor/psychologist/special needs assistant? What possibilities for children's voice exist within this space? Does this school feel like any/every other school? What opportunities for surprise, heterogeneity and new encounters are there in this school? How do I see the roles of different workers (and other adults in this space)? What are the experiences of learning and teaching for all parties?

'Pathoplasty' is a term used to describe the deadening of an institution, the rise of the 'ça va de soi', and importantly, the infraction of what should be the first law of any institution or practice-do not harm (Oury and Roulot 2008; 2007b). If this principle of 'do not harm' is to be taken seriously, careful institutional analysis could help us to understand 
the ways in which the institutions themselves may be harming people housed in or involved with them, be they students, patients, staff or wider communities. Engaging in honest reflections about, for instance, those aspects of school life that profoundly shape children's educational experiences such as the nature of school's relationships with parents, in some cases the elimination of breaks for play, tacit assumptions and even prejudices associated with class or ethnicity, or unwillingness of staff to countenance that one's own practice might be contributory factor in a child's 'acting out'. These factors, and many others, inflect and can corrode the experiences of children or young people as they are shaped by those institutions in which they spend so much of their lives.

\section{The Experience of Education}

Prior to cognition and representation, we participate in and inhabit the spaces of our institutions. Rather than adopting an image of thought for education and learning that prescribes a priori the categories through which phenomena and experience can be identified, classified, and evaluated, real learning, learning that takes hold of one, tends to be a more elusive and unpredictable affair. The concept of thought without a prescribed image describes the experience of those immanent approaches to teaching, thinking and learning that allow for the moment of surprise when 'something happens'. To arrive at this point requires an anexact though rigorous experimental methodology on the part of teacher and institution. Rather than being solely concerned with demonstrating 'education has happened' by measuring outputs, attention is paid to the experience of education.

Gilles Deleuze described learning as an apprenticeship of signs-different materials emit different signs, like archives, genetic material, the sea-and he suggested that we need to find ways of becoming sensitive to signs in our material, thinking, and sensory encounters. The images that we invoke when thinking about education make a difference to what we notice and attend to in the educational experience. In the case of 'thinking-with' the material and becoming sensitive to the subject matter, an open, creative attention is needed by teachers in order to notice what is happening with children. Experiences of hesitation that force us to think are part of educational experiences, that is, of the encounter with the unknown. There is a difference between this kind of experience and one that involves simply receiving, however well these might be communicated, ideas and thoughts from the teacher (Biesta 2013b). Thinking can feel violent and disturbing, something seldom acknowledged in the images of smooth progression that one finds in discourses of life-long learning. Indeed, it may be the case that genuine educational experiences involve both the force of an encounter that sparks interest and the slow shifts in sensibility that are involved in any apprenticeship.

If transformative experiences of learning and of thinking involve opening to something other and becoming something other than our familiar selves, without quite knowing what this will bring or mean, this can be felt as a force that is not readily integrated, and as both discomfiting and exhilarating. In one conversation with children during our collaborative project, "Art and Philosophy in the Classroom", Katy Fitzpatrick and I talked about the concept and experience of the 'invisible', as we tried to imagine with them all that is real, and perhaps sensed, but remains unseen: the sound waves flying about our heads, resonating with our skin and cochleas, the light waves, magnetic forces, text messages, songs on the radio. We imagined thinking about what is happening 'if your ma is talking to your nana on the phone' and asked the children to wonder about how this works-are their 
voices flying over our heads, and how do vibrations turn into language we hear and understand through our technological devices? When the children responded confidently that technology allowed for the operation of mobile phones, and we asked, 'But how..?' At that moment, one could see from their faces, bodies, and sighs that, as one whispered, 'I have never thought about it..'. The technological devices were no longer ready-to-hand. Learning begins with encounters that stir up desire, curiosity, perplexity, passion, imagination, but also generate confusion and disturbance. This involves creating conditions and atmospheres that allow for open collective enquiry, study and wondering.

The nature and feel of the space inflects in important ways the conditions for learning, thinking and experience. Jean Oury, drawing on the poet Pongé, describes this as the construction or fabrication of the pré-, a notion that does not translate well into English, but which means working with the pre-predicative, pre-representational, pre-cognitive space so that something might happen. It is a matter of creating a space in which thinking and creativity may happen. In work with children and adults this often means identifying and removing in advance those preliminary obstacles to thinking and speaking such as: I might be wrong; There is a right answer; I will look stupid; We are all supposed to agree; I should have clearly formed ideas; I have nothing to say. We tell them that there are no right answers in art and philosophy, though there are better and worse responses; that humans have been thinking about these questions over thousands of years so we won't get the answer today; that everyone has ideas and those ideas matter; that we won't agree with each other. To use Oury's language, we perform a kind of asepsis, to clear the space, allowing for other potentials and for different bridges and connections to be made. What matters in this space is often those moments at which something happens for those of us involved in the project or in classrooms. Experiences like these are difficult to name or describe because they mark a gap, hesitation, or insight, or something felt that is more pathic than affective or nameable as a determinate feeling. Learning, then, does not involve recognising the familiar or the prescribed. Learning involves at its origin an experiential undergoing that is transformative for the subject. This kind of language can seem 'vague' or 'fuzzy' for some. When learning is described in terms of processes of emergence and meaning-making, the certainty of the language of the technocrat might be attractive, but will offer little of value to support experience in and of education. This is in part why Elizabeth Ellsworth (1997) calls the lived experience of pedagogy, an event and process through which the teacher is invented as teacher. It is a responsive engagement with what is different from ourselves, what Winnicott will call a 'transitional' or 'holding space', a concept adopted by Oury and Guattari when they think about creation.

What then is meant by this experience? And how can it happen? Developing the capacity for creative and open attention is essential. One can come to learn to observe in detail, to stay with something, and to become absorbed in a thing, a question, or a problem. This itself requires trust because "the feeling of trust makes experience a field of experimentation [giving oneself over], the condition for every form of creation" (Stengers 2011), opening oneself to that which is not oneself. Barbara McClintock described her work in molecular biology in terms of a kind of absorption and careful attention that allows for a particular and intimate kind of knowing. Ellsworth (2005) argues that one must think of the force of pedagogy to develop a more expansive understanding of pedagogy as a pedagogical address that extends beyond the teacher, or one's fellow students. Just as the artists Krzysztof Wodijcko's and Maya Lin's works can be understood in terms of performing civic pedagogy, Ellsworth maintains that we are taught in many ways: in essence pedagogy is that which puts us into relation with the unthought and unknown, the moments that language fails us and we don't know what to say, or the moments when we forget 
ourselves. Yet, the learning or pedagogical experience is not simply a matter of grace that may or may not befall us. Cultivating capacities for expansive and creative attention and the work on the part of teachers to spark interest and to sustain attention makes such moments considerably more likely. Paying attention to the milieu, atmosphere, heterogeneity, or the entours of institutions helps to change the existential experience of the space, including pathic experience through which we are moved directly by the 'feel' or 'climate' of a place. Experimental changes cannot be introduced monolithically but rather require collective navigation, sensitivity and judgement on the part of those involved, in particular staff. Ratnapalan and Reggio's (2012) careful descriptions of this 'climatic phenomenology', the space that allows beings to think and move, in which pathic modes of sensing are singular for each of us, reveals a kind of movement that precedes sensation, akin to, though not equivalent to, what Deleuze might call 'transcendental sensibility' in the sense that it exceeds 'lived experience'. Jean Oury and Guattari argue there is more work to be done in institutions beyond clearing the spaces of whatever hierarchies and prejudices persist, including the distribution of work, roles and responsibilities within the institution. Instead of grace, one must seek to 'programme chance and surprise' or tuché.

\section{On Living Institutions: Atmosphere and the Pathic}

This argument that when thinking about education, we need to think about experience rather than visible or measurable outputs will be challenging for some. The suggestion that the educational experience involves chance and encounters, even if such chance and encounters can be programmed to some extent, will no doubt cause further difficulty, as it leads one from the sense that being a diligent teacher will ensure that students will learninstead the reverse is the case, sometimes students learn, indicating that perhaps you have managed to teach something. The position that Ellsworth and others adopt is not a prescriptive position but rather a descriptive one that tries to communicate something of the experience of what it is like to learn something. If it de-centres the teacher, it is only to create greater attunement to the complexity of relations and dynamics at play in institutions in terms of human relationships as well as the different kinds of qualitatively different encounters that are possible within the institution, from horticulture, to poetry, to buying something in the shop, to offering one's own idea.

Unlike movements in anti-psychiatry or de-schooling, Jean and Francois Oury, Tosquelles and Guattari did not seek to get rid of institutions: Jean Oury explains that institutional pedagogy is not an 'anything goes' but involves a rigorous structure that exploits competences regardless of designated roles or functions - the cook who nurses, the patient who fixes machinery, the cleaner who gives injections. Institutions exist wherever there are rituals, conventions, rules, or laws. Even having a cup of coffee with a friend can be an institution as opposed to an 'establishment' which is in direct relation with the State and which has a tendency to the kind of technocratic logic and simplism (as Jean Oury (2007b) calls it) which undermines the rich, living and experimental nature of institutions. Having good intentions is insufficient for an institution to be effective. The politics of pity and benevolence can serve to consolidate asymmetrical relations of power, giving only some the authority to speak and to be listened to.

Thinking about the institution rather than the isolated individual offers an important counter-point to the tendency of psychoanalysts and psychologists to lock themselves (and their patients) into individuated relations in their offices, suspending from consideration the 
complex forms of social alienation and collective life with which those living and existing in institutional settings must necessarily engage (Oury 2007a, b). Thinking about the possibilities of life in institutions means generating potentials for collective life and collective forms of experimentation within institutional settings. If one discovers that in a school some children are spoken of in individualised pathological terms, in particular in relation to familial background, the ethic of institutional analysis demands that attention be paid to the way in which the world and the complexity of relations of life beyond the institution, including poverty, inequality, sexism, and racism 'infiltrate' school discourse. The purpose of institutions is not then to establish roles, functions and status but rather to institute exchange, or what Weiszäcker calls commerce, but for commerce, heterogeneity is required. Rather than frameworks of generalised equivalence, the rich composition of subjectivity and of encounters is privileged in order to preclude segregation and bureaucratic predictability. In schools, this can mean undoing assumptions about who is competent to teach, or re-thinking the de facto operation of 'school-as-barracks' which segregates age groups into different rooms, curricula and levels. It might involve thinking about pedagogical relationships with wider communities, which diagrammatically, and cartographically, would involve devising spaces or activities through which an 'encounter' might take place.

Rather than trying to figure out "best practice" or "evidence-based practice" it might be more helpful to undertake a careful and collective analysis of the institution at hand, be it a psychiatric institution or a school, treating this specimen as singular, and maintaining an open, responsive and reflexive process of engagement. Institutions have their ebbs and flows, and it is not always clear why institutions move from an atmosphere of energy and animation to depression and dullness. The task for staff, students and the wider community, in the case of the school, is to explore, experiment and tinker to find ways of allowing spaciousness and heterogeneity to emerge: in this sense one could be said to be working with the 'manure' of the institution. Whilst, as we have noted, the image of the gardener is a popular one and whilst budding student-teachers are keen to identify themselves with an uplifting imaginary, that particular image of the gardener or horticulturalist tends to imagine someone who may be responsive or sensitive to a limited extent but who ultimately retains control and predetermines the ends of the pedagogical engagement. Such gardener-teachers decide where to weed, which plants to select, and they organise the space in accordance with their tastes and dispositions. They need some competence in terms of responsiveness, often construed in behavioural management terms, but control and authority lies with them, whilst they feel the satisfaction of raising young seedlings, watering and nourishing them as required. Rather than thinking about the figure of the teacher as (heroic) gardener, institutional analysis turns its attention to the space of the institution itself, including what Oury, following Deligny's description of the 'alentours', calls the 'entours'.

Thinking not just of the garden and its manifestations but of tending to the muck, mulch, manure or culture, that which is invisible or underlying (sous-jacent), invites and sustains a different kind of tending and care. A number of different words, images or concepts are used to speak of this: milieu, atmosphere, pathic, invisible, manure, Stimmung (Oury 1998, 2000; Oury and Roulot 2008). These have resonance with one another, even if they are not entirely equivalent. Nonetheless, the notion that a teacher's job (alongside others who share the collective life of the institution) is in large part to tend to the milieu or atmosphere may seem an elusive proposition to some teachers. Yet, as Jaarsma reminded us, teachers and students (and parents) will recognise intuitively that different milieus have different feels, qualities or sensations (that tomato in outer space). Some classes feel consistently disconnected, irrelevant, dull, tedious, and others animated and sparky. 
Tending to the milieu or atmosphere means a number of things: cultivating points of distinctiveness and difference rather than homogeneity and standardisation; creating opportunities for diverse forms of exchange and commerce; getting rid of presuppositions and prejudice; creating a space of the 'pré-', that is a space from which something can emerge that is not traversed by prejudices and expectations. These are more like experimental recipes than performative indicators. The provisional 'success' of transforming a milieu so that it becomes more open and rich is gauged pathically and sensed directly, rather than described cognitively and measured retrospectively. To speak of the pathic is not quite the same as speaking of intuition as it involves another kind of directness, the kind that any teacher-educator who engages in school placement knows when he or she walks into a school or classroom. Some classrooms are animated, some dull, some tinged with fear and one cannot say precisely why. The pathic is directly sensed and the pre-pathic is the 'contact' that cannot yet be formalised but which has something that communicates attunement and agreement, understood as resonance with the 'other', or indicates the moments where 'something happens'. Even though atmospheres and milieus are invisible and intangible, this makes them no less real. Before thinking about, or trying to figure out, the world, we inhabit and participate in it directly; before even having a sense of self, we experience the world pathically and when we are in relation with an other, we feel ourselves to be at the level of the pre-pathic (Oury 2000, p. 3).

To try to define generic recipes for institutions to follow in order to create spaces of tranquillity, trust and emergence makes little sense given the process involves bricolage, experimentation, and constant re-visiting required in order to keep instituting the potential for heterogeneity and encounter. However, there are some practical strategies to 'clear' the space and perform the kind of asepsis Jean Oury outlines in order to undo hierarchies of inequality, in particular since such hierarchies silence some and rendering them voiceless or less credible. Historically, Célestine Freinet's printing press was one example of creating a sense of responsibility and connection amongst not only children in a school, but across wider communities. Mediators, like the printing press, can play an important role in constructing different potentials for exchange by intervening in established and rigid hierarchical relationships. Principals and teachers could also reflect on and diagram the ways in which power, expertise and authority circulate through the spaces of their institutions, and explore more honestly their own investments in maintaining a status quo that consolidates their dominance, where this is the case. Paying greater attention to the lived quality of the space of the classroom or school, and creating a 'strangeness of being' that can enliven learning and curiosity can also undo viscerally lived presuppositions that harden institutional environments.

\section{Experiments in Thinking: From Insight to Ethics}

This is not a 'free-for-all' conception of experimentation. Institutions need constraints and structures to allow for creativity, learning, thinking, and the transformation of subjectivity. It is not difficult to imagine the kinds of activities that might be undertaken with young children in schools to allow for such experimentation, in particular since young children are not interested in product so much as process, and they enjoy affective and sensual responses, in particular those that are playful and material. Liselott Olsson (2012) in her wonderful descriptions of pre-school children maps the humour and mischief of young children as they animate their letters and in learning to write (fiery letters, shaky letters, 
freezing letters) and play with their own fascination at the affect, image, word composition. When frames, agendas and filters only allow us to see some things as worthy or of value, wonderful opportunities for learning experiences may dissipate. The adventure of ideas as the children play with their objects and letters in the pre-school classroom she describes makes the world become both defamiliarised and renewed. In Olsson's writing, she shows what the children have done and she thinks about this, rather than trying to dissect it or offer causal explanations or universal theories about the nature of the child. Indeed, she resists the idea that predetermined outcomes are effective or even useful when it comes to children's learning. Instead, she is attuned to the sense of the event for the child-the moment in which the playfulness with literacy is welcomed and experimented with, taking on the character of a bodily encounter. What is clear is the importance of the content of knowledge-this is not an approach to education that is simply led by the interest of the child - and then finding and responding to creative and complex approaches to knowledge. Olsson describes the rigorous efforts to prepare and construct an open space for children so that all parties can engage in collective experimentation - teachers and children, and where the children's desire is activated, the teachers do not stand back but work and co-enquire with them in generating questions and problems.

MacLure (2013; Pearce and MacLure 2009) also underline the importance of wonder in pedagogy and in research. Inspired by images of Wunderkammer, cabinets of curiosities, MacLure reflects on the way in which objects precious to children are often taken, confiscated or hidden in a teachers' desk when they enter the space of the classroom because of their perceived potential for disruption. She reminds us of the bonds that children have with their objects and describes the objects made by one 9 year old child called Sinéad who would make assemblages of found objects which she would tuck away in different places known to her but not others. How might classrooms be transformed were these objects to be liberated, so to speak, given the "intimate contact this involves between objects and children's bodies" (232)? Echoing this creative logic, in an art and philosophy workshop we facilitated with teachers and artists, one teacher reflected on the possibilities of thinking about art classes differently, and potential for de-familiarisation and wonder were readymades and found objects to be placed in unexpected spaces in the school and classroom.

Reflecting on the examples of philosophers like Liselott Olsson and Maggie MacLure, in particular the ways in which their writing communicates the joy and surprise that arises at those unexpected moments of connection and imagination in pedagogical situations, or the moments when the teacher or researcher notices what matters to children and creates the conditions to activate these intimate engagements, it seems important to indicate some of the ways in which creative and inventive methods can institute heterogeneous relations. What is required for these to 'work' is for the space to be cleared (as described above) so that each child knows that his or her voice, ideas, sensibility and dispositions count and matter. It also means acknowledging that experimentation and engaging in collective forms of enquiry or creative exploration involves exposure (Biesta 2013a) and that there are no guarantees in experimental pedagogies. Olsson cites Dahlberg who says that this involves a pedagogy of listening and "not so much a process of labelling, identification, recognition and judgement - it is more about an ethics of an encounter" (2009: p. 41) Developing a more attenuated sense of and attention to singularity, or 'ecceity', John Llewelyn (2015) suggests that Gerard Manley Hopkins' etymological innovation with 'ecceity', rather than John Duns Scotus' 'haecceity', intimates the 'ecce'-Behold! Look! —at play with singularity, the thisness of each existent, including humans. At the heart of experimental pedagogy and experiments with institutions one finds not only the commitment to the singularity of the other, and the respect for the singularity of the other, but also, through 
creative and open attention, the feeling for and acknowledgement of the singularity of all existents.

Fernand Deligny says that the human is gesture and form before language. The slightest gesture, word or silence can allow life to begin anew or to freeze. When Oury and Deligny speak of the 'least of things', they ask us to become attuned to the subtle moments in existence, to a gesture, a word, or a smile, and to attribute to such things the significance that they may deserve. This is not the moment of mastery ("I finally get it!") but rather points to those ephemeral shifts in sensibility, ideas and perceptions where the world opens, and the student or child or teacher opens to the world. I think also of some of the men with whom I worked in prison speaking of precious and all too rare moments of kindness or acknowledgement in classrooms that they 'keep' or 'collect' and 'cherish', sometimes holding them for decades. Even if those moments may not have been sufficient to change the trajectory of their lives, they still inflect and nourish them. Something of this is at play when Guattari poses the question of how to create a classroom as though it were a work of art. Such a creation would mean tending to the actual and potential aesthetic, pathic, and subjective encounters that (could) emerge in such a space and it would mean thinking about how the specific space of the classroom 'hangs together' or doesn't.

Sometimes, when doing art and philosophy with children we deliberately assign tasks in the hope that a sense of wonder, curiosity, and attunement to the singularity of things, our bodies, each other, and works of art can be evoked. Most of the tasks are rather gentle and sometimes a little odd, but they come from a sense that the world can be enlivened rather than flattened, and they try to resist the general equivalence that homogenises and pollutes the psyche and socius by using simple gestures, movements and acts: looking, feeling, hearing, listening, touching, thinking, and sensing. The pathic involves being moved prior to cognition and invites sensations and wonderings in familiar situations and things. One might ask who was the first person to come up with the idea of an artwork (knowing this is a technically incorrect question) to create a sense of interest in that mythical moment that someone made a mark, chipped at a stone, and said 'Ecce! Behold this!'. Exploring philosophical concepts like memory and asking the children to think about the imaginary auto-biography of a thing, can open up other lines of enquiry: Do wooden things like to hang out with other wooden things, like pencils, tables and trees? Does a pencil-case remember all the hands it has passed through? What would it say if it did? Taking ordinary objects and things and defamiliarising them, perhaps bringing something from nature into the space of a classroom (a lump of dirt..) or taking something from the classroom and curating it in the wider natural spaces that may be near a school or locating it in an unexpected place within a school, or re-patterning everyday things like twigs and leaves to make ephemeral artworks, or asking the children to write Alien instructions to give this thing or being a wide range of sensory experiences that it wouldn't have encountered if it lived in a suspended bubble in space are all strategies to creates the conditions for different kinds of experiences and questions. Doing so helps to create the conditions for an encounter, for a pedagogical experience, with the sense and conviction that for some, as those ideas start darting, crackling, and percolating, they may begin enquiring with and through contemporary art practice and philosophy about all manner of things from the origins of the universe, the life of a louse, to whether a urinal can be a work of art.

Experimenting with and in institutions requires an ethics that is sensitive to the singularity of the other in all situations. At times it is suggested that speaking about concepts and ideas in communities of philosophical enquiry is somehow less intimate or exposed than 'making an artwork'. This is a profound misunderstanding of what pedagogical encounters can mean for someone and it reifies certain kinds of 'creative' encounters. On 
the contrary, for one child, it might be transformative simply to have spoken and been listened to. For another, it will be because they are suddenly sensibilised to the richness of things.

Much of what we have said 'gives permission' to pay attention to those invisible, intangible dimensions of institutional life for which language does not come readily, not only because they are not valued or acknowledged in technocratic systems, but also because they come from the space of the 'pré', the pathic, or more precisely oftentimes the pre-pathic. The stumbling to articulate oneself that is often experienced is because what is at play is the genesis and emergence of thoughts, words, gestures and ideas. Jean Oury, like Erwin Straus, thinks of pathic in terms of 'sym-pathy', different from empathy which merges with its object. Sym- on the other hand keeps the sense of 'being-with-the-other'. To 'welcome' the other means respecting them as a subject, says Oury, acknowledging that there is something opaque about them, something that cannot be grasped or mastered. At a minimum, the sense that someone knows that they count and they matter for someone else is significant. The difficulty for Oury, in particular in the case of psychotics, is to come to occupy the same landscape as another but when we do encounter the other we exist in the same landscape. We sense when someone is in the same landscape and when they are not: for example, the teacher who scans the room and only half listens to a child's answer to the question that she or he has directed towards the child. Likewise when a child is prejudged on the basis of his or her background or family, he or she can feel that they exist in different universes from their teachers.

Buber's idea of the pedagogical relationship is resonant with Oury's conception of the ethical relationship with the singular other, however Oury is, I suggest, more sensitive to the world and to the ways in which collective forms of life, beyond the master and student, may be needed for a pedagogical or learning experience to occur. Both Buber (1947) and Oury keep alert to the moments of this shift, the 'something happens' that is less than an epiphany, but rather offers direct insight (Oury and Roulot 2008). Yet, receptivity to the other also involves being sensitive to what is happening, beyond Buber's idea of the aliveness and presence of the teacher. It is not a matter of identifying the correct diagnosis or classification of the other, a tendency that operates with totalising and standardising logics, but rather of finding a way to be with the other. This involves experience and the development of existential competence. Whilst Noddings' (1984) conception of care remains important, Oury's (2007b) conviction that 'the hospital (or school) is ill' and it requires care, opens up the idea of what care means beyond caring relationships. If we are to be with the other, this means taking account of the 'style' of the other, and learning how to be-with in different ways in different encounters, as well as paying attention to the embodied, material, relational spaces in which we co-exist. Good teachers come to have a strong sense of the singularity of each child in the classroom. The question is how to create the conditions in institutions that allow for not only that singularity to be acknowledged and accepted, but also allow for singularisation and becoming to be cultivated in the collective life of institutions. Perhaps, if nothing else, schools as institutions might commit to that principle of 'do no harm', that would allow people at a minimum to exist and to become. But it would be even better if they could also think of how to construct and tend to their atmospheres and milieus to allow them to become complex, collective spaces of emergence, surprise, and experimentation, so that they are polyphonic, heterogeneous, sensitive to each singular existent, attentive to the importance of tiny details like saying hello or a smile. Oury often returns to Antonio Machado's words "the road is made by walking". It is this delicate, precarious, open, experimental, critical sensibility that can allow institutions to become living spaces. 


\section{References}

Biesta, Gert. 2007. Why 'what works' won't work: Evidence-based practice and the democratic deficit in educational research. Educational Theory 57 (1): 1-22.

Biesta, Gert. 2011. Philosophy, exposure, and children: how to resist the instrumentalisation of philosophy in education. Journal of Philosophy of Education 45 (2): 305-319.

Biesta, Gert. 2013a. The beautiful risk of education. Boulder: Paradigm.

Biesta, Gert. 2013b. Receiving the gift of teaching: from 'learning from' to 'being taught by'. Studies in Philosophy and Education 32: 449-461.

Buber, Martin. 1947. Between man and man. London: Kegan Paul.

Deleuze, Gilles. 1994. Difference and repetition. New York: Columbia University Press.

Ellsworth, Elizabeth. 1997. Teaching positions: Difference, pedagogy and the power of address. New York: Teachers College.

Ellsworth, Elizabeth. 2005. Places of learning: Media, architecture, pedagogy. New York: Routledge Falmer.

Jaarsma, Ada S. 2016. Design, disability and play: The animal politics of education. Gender and Education 28 (2): 195-212.

Llewelyn, John. 2015. Gerard Manley Hopkins and the spell of John Duns Scotus. Edinburgh: Edinburgh University Press.

MacClure, Maggie. 2013. The wonder of data. Cultural Studies: Critical Methodologies 13 (4): $228-232$.

Maldiney, Henri. 1991. Penser l'homme et la folie. Grenoble: Jerôme Millon.

Noddings, Nell. 1984. Caring: A feminine approach to ethics and moral education. Berkeley: University of California Press.

O’Donnell, Aislinn. 2013. Unpredictability, transformation and the pedagogical encounter: Reflections on 'what is effective' in education. Educational Theory 63 (3): 265-282.

Olsson, Liselott. 2009. Movement and experimentation in children's learning: Deleuze and Guattari in early childhood education. London: Routledge.

Olsson, Liselott. 2012. Eventicizing curriculum: Learning to read and write through becoming a citizen of the world. Journal of Curriculum Theorizing 28 (1): 88-107.

Oury, Jean. 1998. Il, donc. Vigneux: Éditions Matrice.

Oury, Jean. 2000. Le pré-pathique et le tailleur de pierre. Chimères 40: 1-7.

Oury, Jean. 2005. Le collectif: Le séminaire de Sainte-Anne. Nîmes.

Oury, Jean. 2007a. Rencontre avec le Japon. Vigneux: Éditions Matrice.

Oury, Jean. 2007b. 'The hospital is ill': an interview with Jean Oury. With David and Mauricio Novello. Radical Philosophy 143: 32-45.

Oury, Jean, and Danielle Roulot. 2008. Dialogues á la Borde: Psychopathologie et structure institutionnelle. Paris: Hermann Éditeurs.

Pearce, Cathie, and Maggie MacLure. 2009. The wonder of method. International Journal of Research \& Method in Education 32 (3): 249-265.

Ratnapalan, L.M., and David Reggio. 2012. Erwin Straus and the pathic. History of Psychiatry 23 (3): 291-304.

Smith, Zadie. 2002. On beauty. London: Penguin.

Stengers, Isabelle. 2011. Thinking with whitehead. Cambridge: Harvard University Press.

Tosquelles, François. 2003. Cours aux éducateurs. France: Champs Social. 